\title{
KECEPATAN TINGKAT PENERIMAAN DAN PERILAKU KONSUMEN TERHADAP PRODUK LAMA YANG MENGALAMI PERUBAHAN DAN PRODUK INOVASI BARU DALAM UPAYA MEMASUKI DAN MEREBUT PASAR
}

\author{
Leli Deswindi \\ Email: 1deswindi@lecturer.bundamulia.ac.id
}

\section{Penulis}

Leli Deswindi adalah staf pengajar tetap di Jurusan Teknik Industri, Universitas Bunda Mulia, Jakarta dan menjadi koordinator dalam bidang manajemen industri. Bidang peminatan: service quality, manajemen jasa dan manajemen pemasaran.

\section{Abstract}

Effectivities of the promotions have always become a hot issue in marketing field. Several marketers don't measures the effectiveness of the campaign result. Experiences proved for the decreased of using some traditional method in the campaign activity such as commercial advertisement in electronic media. Marketers prefer to choose the application of other promotion methods. Integrated Media Communication (IMC) is the application of the total campaign tools as an integrated method that has been chosen nowadays. The goal of the $I M C$ is to strengthen the company position in every part of the Product Life Cycle (PLC). Begin with the product development, introduction, growth, maturity and decline. How to understand customer in order they will become a loyal to a product, is a very complex situation. This Journal focus on the study to understand the period of the acceptance from customers in term of a new product development or a product improvement. The effort of the marketer to build the relations with the customer is the key to maintain and learn about the future needs from customer, maintains the market share, increased the growth of a company and returns the scale of profitability.

\section{Keywords}

Manajemen pemasaran, perilaku konsumen, promosi 


\section{PENDAHULUAN}

Suatu perusahaan didirikan dengan tujuan untuk mencari keuntungan. Bagaimana keuntungan tersebut dapat dihasilkan tentunya dengan melaksanakan aktivitas penciptaan output suatu produk atau jasa, yang kemudian output tersebut ditawarkan untuk dikonsumsi kepada konsumen. Dengan menjalankan proses ini secara berkelanjutan, maka akan diperoleh suatu keuntungan yang dapat memberikan nilai (value) bagi perusahaan.

Salah satu faktor penggerak berjalannya operasional perusahaan adalah dengan menjalankan aktivitas pemasaran secara tepat dan terarah. Prinsip dasar dari proses pemasaran menurut Kotler (2006) yang utama adalah bagaimana kita dapat memahami keinginan dan kebutuhan (needs and wants) dari konsumen. Suatu produk yang dapat memenuhi kebutuhan dan keinginan dari konsumen tentunya akan terjual dipasaran dengan syarat target pasar produk tersebut tentunya harus memilki daya beli. Konsumen yang menjadi target harus ditentukan terlebih dahulu, untuk dapat memastikan konsumen sebagai pembeli aktual (actual buyers) yaitu kelompok masyarakat yang akan membeli produk atau jasa yang dihasilkan oleh suatu perusahaan dan memiliki daya beli, maka terlebih dahulu perusahaan harus melakukan penelitian pasar.

\section{DEFINISI PERILAKU KONSUMEN}

Ada beberapa definisi perilaku konsumen yang dikemukakan oleh para pakar. Diantaranya menurut Engel (1995), perilaku konsumen adalah tindakan yang langsung terlibat untuk mendapatkan, mengkonsumsi, dan menghabiskan produk atau jasa, termasuk proses keputusan yang mendahului dan mengikuti tindakan ini. Sementara, Loudon dan Bitta (1988) lebih menekankan perilaku konsumen sebagai suatu proses pengambilan keputusan yang mensyaratkan individu untuk mengevaluasi, memperoleh, menggunakan, atau mengatur barang dan jasa.

Menurut Kotler dan Amstrong (2006) mengartikan perilaku konsumen sebagai perilaku pembelian konsumen akhir, baik individu maupun rumah tangga yang membeli produk untuk konsumsi personal.

Dari definisi-definisi diatas dapat ditarik beberapa kesimpulan, yaitu:

a. Perilaku konsumen menyoroti perilaku individu dan rumah tangga.

b. Perilaku konsumen menyangkut suatu proses keputusan sebelum pembelian serta tindakan dalam memperoleh, memakai, mengkonsumsi dan menghabiskan produk.

Memahami perilaku konsumen meliputi perilaku yang dapat diamati seperti jumlah yang dibelanjakan, kapan, dengan siapa, oleh siapa, dan bagaimana barang yang sudah dibeli dikonsumsi. Juga termasuk variabel-variabel yang tidak dapat diamati seperti nilai-nilai yang tidak dimiliki oleh konsumen, kebutuhan pribadi, persepsi, bagaimana mereka mengevaluasi alternatif dan apa yang mereka rasakan tentang kepemilikan dan penggunaan produk yang bermacam-macam. 


\section{MODEL PERILAKU BELANJA KONSUMEN}

Untuk dapat memahami perilaku belanja dari konsumen, Kotler (2006) mengemukakan bahwa terdapat tiga tahapan yang harus dilalui, yaitu:
a. Aktivitas promosi dan stimulus lain
b. Kotak hitam pembeli
c. Respon dari pembeli

Model perilaku belanja konsumen menurut Kotler (2006):

\section{Gambar 1. Model of Buyer Behavior}

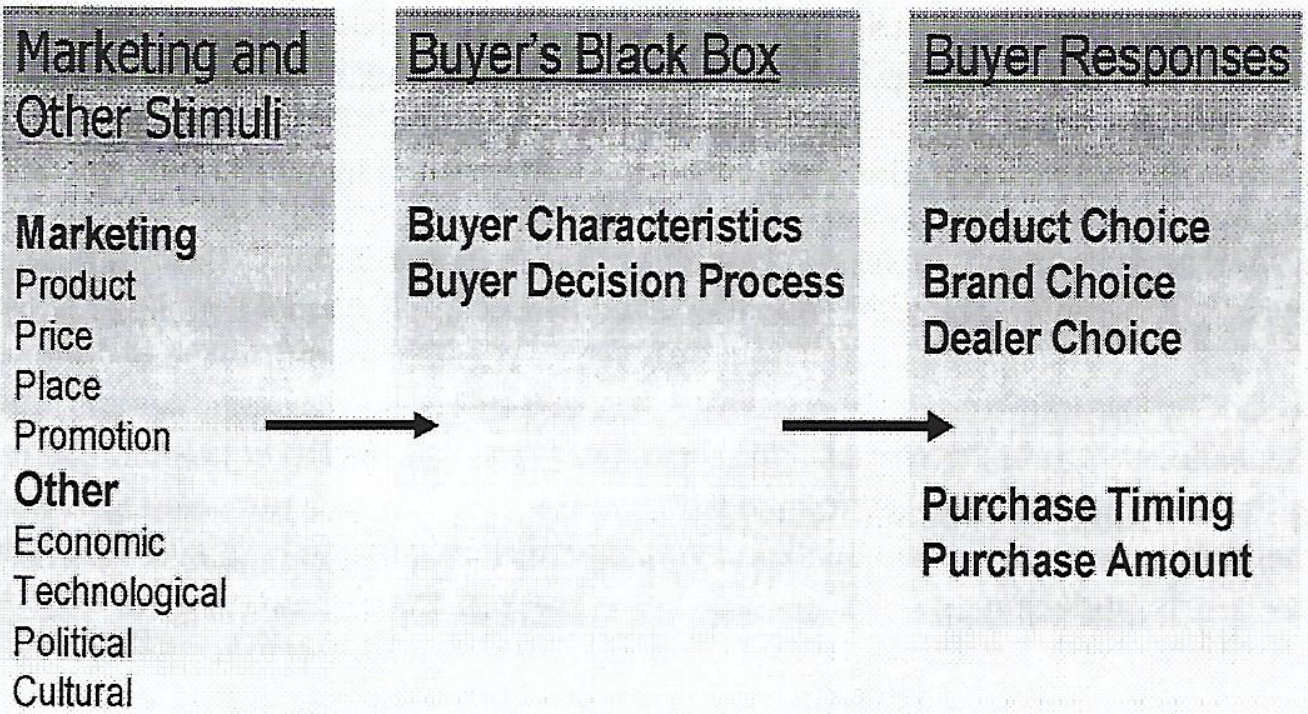

\section{PEMASARAN DAN STIMULUS LAIN}

Faktor pertama dalam model perilaku belanja konsumen adalah aktivitas perusahaan dalam memasarkan produk diiringi pemberian rangsangan yang dapat mempengaruhi persepsi dari konsumen. Pelaksanaan strategi pemasaran inti yang dikenal dengan konsep 4P sangat berpengaruh dalam pencapaian tingkat pertumbuhan yang tinggi, pangsa pasar dan tingkat keuntungan dari suatu 
perusahaan. Faktor strategi pemasaran tersebut diantaranya menganalisa para pemain atau pesaing, termasuk didalamnya inovasi, produk baru, pelaksanaan distribusi, perubahan harga atau aktivitas promosi. Dalam perkembangannya saat ini, aplikasi dari aktivitas promosi tidak lagi memilih menggunakan salah satu sarana promosi saja, tetapi banyak perusahaan yang menerapkan menjalankan komunikasi pemasaran secara terpadu (IMC) yang lebih terarah. Dalam keseharian dapat kita lihat contoh perusahaan telekomunikasi Telkomsel. Aktivitas promosi yang dilakukan bukan hanya melalui iklan pada media cetak dan elektronik saja, tetapi juga menjadi sponsor pada berbagai acara musik yang sifatnya langsung berhubungan dengan masyarakat sebagai konsumen dan juga berbagai acara bakti sosial yang merupakan aplikasi dari corporate social responsibility (CSR) dalam wujud Telkomsel Peduli.

\section{KOTAK HITAM PEMBELI}

Berdasarkan aktivitas dan rangsangan dalam kegiatan pemasaran, semua input yang diterima oleh konsumen akan diolah sedemikian rupa berdasarkan karakteristik dan lingkup pengambilan keputusan pembelian oleh individu. Karakteristik dipengaruhi oleh faktor-faktor seperti budaya, kelas sosial, kepribadian dan psikologi. Faktor-faktor yang mempengaruhi Perilaku belanja konsumen

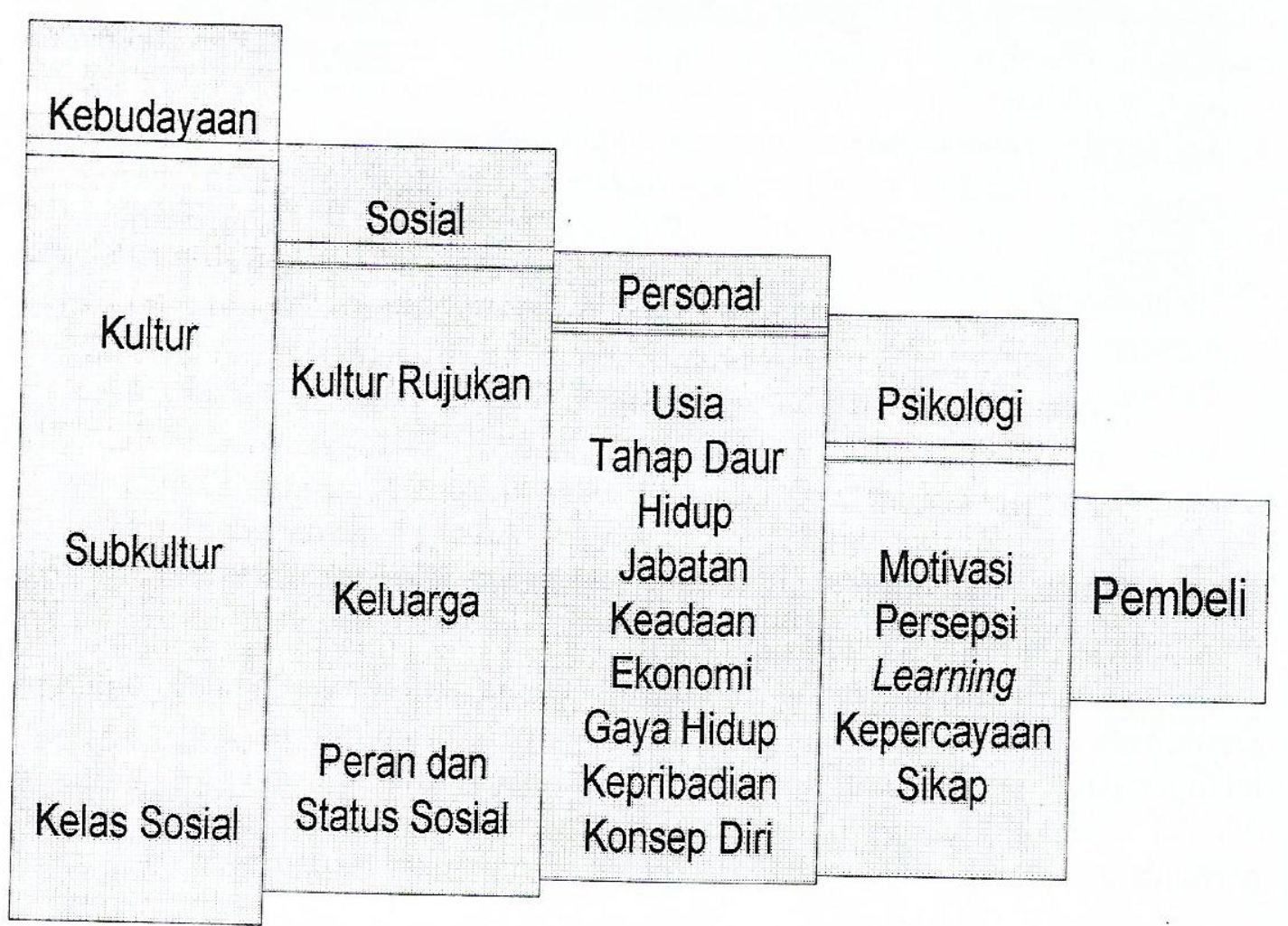

Sumber: Kotler, 2006. 
Peran faktor-faktor tersebut diatas berbeda untuk produk yang berbeda. Dengan kata lain, terdapat faktor yang dominan pada pembelian suatu produk sementara faktor lain kurang dipengaruhi oleh faktor lain. Dalam kenyataannya, dibutuhkan sekitar 1 sampai 5 tahun (www.frontierconsultinggroup.com) bagi konsumen di Indonesia untuk dapat menerima sebuah produk makanan atau minuman yang memiliki bentuk baru. Contohnya adalah minuman nata de coco yang pertama kali diluncurkan dalam bentuk padat. Perusahaan kemudian melakukan inovasi dengan mengeluarkan produk nata de coco dalam bentuk cair yang dapat langsung diminum bersama dengan sari buah. Apabila perubahan menyangkut rasa, waktu yang dibutuhkan oleh konsumen untuk dapat menerima produk baru tersebut memakan waktu yang lebih lama lagi yaitu sekitar 5 hingga 15 tahun (www. frontierconsultinggroup.com). Contohnya adalah minuman isotonik yang ditawarkan kepada pasar sekitar tahun 1980-an. Karena rasanya yang asin dan tidak biasa bagi konsumen saat itu, penenrimaan terhadap produk ini menjadi lambat sekali. Minuman sari buah, teh dan air mineral yang lebih banyak diminati oleh masyarakat pada masa tersebut. Baru sekitar tahun 2000 , minuman isotonik dapat diterima oleh masyarakat dengan Pocari Sweat sebagai leader pada kategori ini.

Bagi makanan dan minuman dengan kategori baru dan menawarkan sesuatu yang lain dengan kebiasaan makan atau norma suatu suku, maka proses yang dibutuhkan untuk dapat diterima oleh masyarakat dapat memakan waktu puluhan tahun. Dengan kata lain, dibutuhkan satu generasi penuh agar kategori makanan dan minuman tersebut dapat diterima oleh konsumennya. Mengetahui suatu budaya atau kebiasaan masyarakat bukanlah pekerjaan mudah. Karena itu, seorang marketer haruslah secara cermat dan hati-hati dalam melaksanakan strategi pemasaran. Banyak perusahaan yang berfokus untuk mengedukasi pasar namun karena berlangsung untuk waktu yang lama, perusahaan tersebut harus putus ditengah jalan. Akhirnya yang menikmati adalah pendatang baru yang relatif tidak memerlukan banyak upaya untuk melakukan edukasi pasar. Perusahaan tentunya membutuhkan kesabaran yang panjang untuk menunggu sampai suatu saat konsumen menerima suatu produk.

Atau lebih mudah lagi melakukan proses penetrasi di mana sebuah kategori sudah eksis, kemudian salah satu merek produk melakukan perubahan dalam cara pemasarannya. Salah satunya dengan melakukan perubahan dalam desain. Ini adalah cara yang biasanya membutuhkan waktu cepat. Desain menawarkan suatu tren yang dinamis, segar dan relevan dengan kondisi zaman.

Faktor strategi para pemain dalam kategori produk juga tentunya sangat berpengaruh, terutama dalam hal distribusi dan komunikasi. Distribusi adalah faktor penting yang membuat penetrasi produk menjadi cepat. Kecepatan penerimaan dalam distribusi dilihat dari dua sisi, yaitu: proses komunikasi yang cepat kepada pasar dan kenyamanan dari konsumen karena memperoleh produk dengan cara yang lebih mudah dan nyaman. 
Karakteristik pembeli inilah yang membuat setiap konsumen sebagai individu menjadi berbeda. Konsumen yang memiliki faktor demografi yang sama dan terpengaruh oleh iklan yang sama, belum tentu memiliki perilaku pembelian yang sama. Individu memiliki persepsi dan kepribadian dan motif yang berbedabeda. Dua individu yang berbeda pada kelas sosial A dan terekspos oleh produk dan promosi yang sama, akan sangat berbeda perilakunya karena mereka memiliki motif yang berbeda. Individu yang satu mungkin memiliki motif sosial dan selfesteem yang lebih tinggi dari individu lain, akibatnya individu dengan motif lebih tinggi akan melakukan berbagai aktivitas yang memberikan simbol atau status yang lebih tinggi. Contoh yang terjadi di lingkungan kita adalah bagi konsumen pencinta kopi tentu akan lebih bergengsi jika menikmati kopi di gerai Starbucks, atau para pencinta donut akan lebih tinggi prestigenya jika membeli pada gerai J'CO.

\section{RESPON PEMBELI}

Tahap ketiga dalam memahami perilaku konsumen adalah tahap dimana keputusan dibuat. Dalam melakukan pembelian, faktor yang menjadi pertimbangan dipengaruhi oleh tingkat kebutuhan akan produk/jasa, keputusan terhadap merek dan pemilihan pemasok. Faktor lain yang juga mempengaruhi diantaranya adalah pemilihan waktu dan jumlah pembelian produk/jasa. Diantara sekian banyak karakteristik yang dimiliki oleh konsumen, yang harus menjadi perhatian utama sebagai faktor yang dapat mempengaruhi respon dari pembeli adalah tergantung dari jenis produknya dan faktor demografi. Bila segmen yang kita bidik adalah remaja, maka faktor strategi perusahaan dan kompetisi menjadi sangat penting. Remaja adalah sangat mudah dipengaruhi oleh iklan dan cenderung lebih mudah menerima produk baru.

Bila segmen yang dibidik adalah mereka yang sudah berumur dan dari golongan menengah-bawah, maka faktor budaya, norma, kebiasaan dan keluarga adalah faktor yang dominan.

Untuk individu yang berasal dari kelas sosial yang lebih tinggi dan berumur matang, maka faktor kepribadian dan keputusan pembelian pribadi akan menjadi faktor yang paling mempengaruhi perilaku mereka dalam memilih, membeli dan mengkonsumsi suatu produk.

\section{KESIMPULAN}

Seiring dengan meningkatnya persaingan antar industri di segala bidang, maka perusahaan dituntut untuk semakin jeli dalam melihat peluang pasar yang tersedia. Perusahaan didorong untuk terus melakukan inovasi dalam upaya meningkatkan pertumbuhan, pangsa pasar dan keuntungan perusahaan. 
Strategi pemasaran memiliki kaitan yang tinggi dalam mempengaruhi keputusan pembelian oleh konsumen. Karena itu pelaksanaan strategi pemasaran tersebut harus ditentukan dengan menganalisa secara mendalam faktor-faktor karakteristik dari konsumen. Faktor yang menjadi dominan dalam mempengaruhi keputusan pembelian konsumen tergantung pada jenis produk dan demografi.

Diperlukan waktu yang cukup lama bagi seorang konsumen untuk dapat menerima suatu produk baru atau produk lama yang mengalami perubahan. Tetapi hendaknya perusahaan harus dapat memperhitungkan dengan baik seberapa besar sumber daya yang dimiliki agar perusahaan tidak putus ditengah jalan sampai akhirnya konsumen dapat menerima keberadaan suatu produk atau jasa di pasaran. Serta perusahaan mampu menjaga keberlangsungan hidup perusahaan.

\section{DAFTAR RUJUKAN}

Engel, James. F, Roger D. Blackwell dan Paul W. Miniard. 2003. Consumer Behaviour. 11th Edition. The Dryden Press, Orlando.

Joewono, H. Handito. 7 in 1 Strategy: Toward Global Competitiveness, Jakarta, Pustaka Bisnis Indonesia dan Arrbey, 2006

Kotler, Philip. Marketing Management Analysis, Planning, Implementation and Control. New York, Prentice Hall, 2006

Kotler, Philip. Marketing Management: An Asian Perspective. Fourth Edition, Singapore, Prentice Hall, 2006

David, L.. Loudon dan Albert J. Della Bitta. Consumer Behaviour. Third Edition. New York, McGraw-Hill Book Company, 1998

Majalah Marketing "Memprediksi Kecepatan Konsumen Belajar", vol. 3, Maret, 2007

Mancini, Mare. Connecting with consumer: How to sell, service and market, New Jersey, Prentice Hall, 2003

Simamora, Bilson, Panduan Riset Perilaku Konsumen, Jakarta, Gramedia Pustaka Utama, 2002 